\title{
Mentoring Doctoral Students in a Developing Society
}

\author{
V. Vishwa Mohan \\ Dept of Library \& Information Science, Osmania University, \\ Hyderabad, India
}

\section{profvmohan@gmail.com}

\begin{abstract}
Research activity should be carried out with utmost care, dedication, and involvement. It is here where mentoring of doctoral students by the research supervisor or guide comes into picture irrespective of the social background of the student. Objectives of the study: 1)To share the experiences regarding the supervision work of Doctoral research, 2) To identify the problems of the Doctoral students, where mentoring is needed, and 3) To suggest solutions for the problems related to mentoring of Doctoral students. The scope of the study is confined to Indian experience. Methodology and analysis: The study employed empirical methods. The data was jotted down from the research and guidance experience of the author for the past 20 years. For this study, 10 aspects were identified against which the student behavior and mentoring needs were assessed. Results of the study: There are considerable instances of misunderstanding on the part of the students, almost a majority of them do not get inclined to do collaborative research on the other hand some of the students turn out to be dropouts and do not bother to continue relation with the Department or the supervisor. The study also suggests some solutions for better mentoring process.
\end{abstract}

Keywords: Mentoring, Doctoral Students, Doctoral Research

\section{Introduction}

When the topic of mentoring Doctoral Students arises, immediately, the question, "Is there any need for mentoring Doctoral Students?" would arise. Especially, when right from the Under Graduate level, the present day students are required to work on assignments, projects, dissertations, seminar presentations, etc. They have been guided through out. When it comes to Doctoral research work, the Doctoral Students are supposed to have research aptitude and the research guide or supervisor is expected to guide the student right from the identification of the research problem till the completion of the research report. Guiding and rectifying the mistakes in the research work and also the research report are part of the duty of the research supervisor. Mere guiding and putting the Doctoral Students on the right track, is called mentoring? It is the basic

Material published as part of this publication, either on-line or in print, is copyrighted by the Informing Science Institute. Permission to make digital or paper copy of part or all of these works for personal or classroom use is granted without fee provided that the copies are not made or distributed for profit or commercial advantage AND that copies 1) bear this notice in full and 2) give the full citation on the first page. It is permissible to abstract these works so long as credit is given. To copy in all other cases or to republish or to post on a server or to redistribute to lists requires specific permission and payment of a fee. Contact 0HPublisher@InformingScience.org to request redistribution permission. function of the research supervisor. Then what is mentoring? Mentoring is something beyond this basic function of the research supervisor. In fact, this is more important than mere guiding. I would say, "Mentoring is more important, without which, the quality of research work will be affected, the research aptitude of the students would not improve, and there will be the instances of dropouts even at the level of 
Doctoral Research." Research has demonstrated that good mentoring is a key variable for determining success in a doctoral program (Adams \& Conley, 1986). Especially in the developing societies, the background and characteristics of the students are different from the students in developed societies. These students are characterized by rural background, regional media, economic backwardness, etc. The students in Indian universities come from different backgrounds, hence, mentoring proves to be imperative in Indian universities.

Further, Doctoral research work is an important academic activity due to which new knowledge would be contributed by the academic institutions, it promotes collaborative research, an understanding and continued relation between the teacher/supervisor and the taught. Thus it builds the academic and research communities. Therefore, mentoring is as important as guiding and correcting the research work. Summers-Ewing (1994) concludes that "people with mentors become quickly socialized to an organization or profession, obtain high-visibility assignments, stay wellinformed of future opportunities and are coached to success." Quoting Jacobi (1991), Dickinson and Johnson (2000) present the characteristic merits of mentoring noted general agreement that: (a) mentor relationships are helping and supportive relationships which help the protégé succeed in school, work or in reaching long range goals, (b) mentoring includes component areas of psychosocial support, direct assistance and role modeling, (c) mentoring relationships are reciprocal in that the mentor has been found to also benefit from the relationship, (d) mentor relationships are personal, and (e) within the mentor relationship, the mentor shows greater professional experience, influence and achievement. Dickinson and Johnson (2000) further state, the psychosocial functions include role modeling, provision of acceptance and support, counseling and friendship.

The mentor/mentee relationship becomes more vital depending on the psychological, social and cultural background of the mentee. Ku, Lahman, Yeh, \& Cheng, (2008) state that, "The mentor/mentee relationship may be even more vital for international graduate students because they are dealing with a high level of cultural adjustment and language barriers, along with attempting to understand the culture of academia." This is quite true, every student has his/her own typical psychological, social, economic, and cultural background that influence his/her behavior.

The observations of Collinson and Hockey (1997) as quoted by Deem and Brehony (2002) are almost the same with the present conditions of Doctoral Research in non-science fields in our university. In non-science fields, students usually choose their own topic and are rarely attached to a research team. Funding for full-time students is not usually tied to the research grants held by supervisors. Training is usually formalized. Students and supervisors often only meet at formal supervisory meetings. The thesis is usually seen as part of the research process. The student is regarded as more autonomous than in science and can usually publish their work under their own name. However, part-time students do not have the same experiences as full-time students and may have different motivations for their study. There may be less access to research training than for their full-time counterparts and fewer contacts with supervisors; Part-time students may prefer to concentrate on methods they will definitely use rather than attending more generic training.

Mentoring of Doctoral students is indispensable to ensure quality research work that needs studious efforts on the part of both the supervisor and the student. The Webster's Seventh New Collegiate Dictionary defines research as "Studious inquiry or examination; especially: investigation or experimentation aimed at the discovery and interpretation of facts, revision of accepted theories or laws in the light of new facts, or practical application of such new or revised theories or laws." This clearly denotes that research is a studious, serious and systematic investigation of facts that are crucial for developing theories, revising existing theories in the light of the new facts, application of the existing theories to evolve dependable solutions to the problems that challenge human life and human society. In view of this every researcher needs to ensure objectivity in interpreting the facts, application of valid, reliable and accurate methods, techniques and measurements 
while carrying out research. Any lapse in these aspects would render the whole research work and its findings misleading, unreliable and devastating.

Therefore, research activity should be carried out with utmost care, dedication, and involvement. It is here, mentoring of doctoral students by the research supervisor or guide comes into picture irrespective of the social background of the student. However, it is more vital in developing societies. Besides keeping the researcher on the right track, developing research aptitude, impressing upon research ethics, motivating for collaborative research and continued relation and friendship are the important tasks the research supervisor has to perform as a mentor. It is to share experiences and views on this important area; this paper is prepared with the following objectives:

\section{Objectives of the Study}

1. To share the experiences regarding the supervision work of Doctoral research.

2. To identify the problems of Doctoral students, where mentoring is needed.

3. To suggest solutions to the problems related to mentoring of Doctoral students.

\section{Scope of the Study}

The study is confined to the Indian experience. Besides Doctoral Students, it also briefly deals with the experiences concerned with supervising M. Phil and Masters level dissertations, in order to have a brief comparison of research aptitude of the students at various levels.

\section{Operational Definitions}

Doctoral Student: Doctoral student is also called or known as $\mathrm{Ph}$. D research scholar. Therefore, research scholar, student (in the present context), are synonymously used for Doctoral Student.

The Mentor: The mentor in the present study is the research supervisor or guide of a Doctoral student. Hence, Guide and supervisor are synonymously used for the mentor.

P G (Post Graduation): The educational programs at Masters Level are called PG courses or programs in India.

Adjudication: The general meaning of the word 'adjudication' is the process of adjudicating. Adjudicating means passing judgment. In Indian universities the term is used to mean the process of evaluation of the thesis to declare whether it is recommended for award of the degree or not.

M. Phil : Master of Philosophy, is an academic research program pursued by the students after Post Graduation prior to Ph.D. that is the Doctoral Research Program.

Viva-Voce: is an oral examination conducted after receiving the adjudication reports from the examiners of the Doctoral Thesis or M. Phil Dissertation and before awarding the Doctoral or M. Phil Degree.

Guidance and supervision are used synonymously.

\section{Methodology}

The study employed empirical methods. The data were jotted down from the research and guidance experience of the author for the past 20 years. The author has the experience of guiding 10 dissertations at Masters Program, 14 M. Phil dissertations, 16 Doctoral Students and adjudication of 13 Doctoral Theses. The experience is a mixed one with students having English Medium and Regional Medium background, Rural and Urban Background. He has supervised and adjudicated works of regular students and in-service men working with State, National and International or- 
ganizations, students with Fulbright Fellowship, Junior Research Fellowship (JRF), and Foreign Students.

For this study, 10 aspects were identified against which student behavior and mentoring needs were assessed. The ten aspects are: 1. Identification of the Research Problem, 2. Agreement for the finalization or formulation of the Problem, 3. Formulation of the Problem and the Hypotheses, 4. Deviation from the Focus, 5. Reporting the Results, 6. Friendliness, 7. Understanding and appreciation, 8. Drop Outs, 9. Developing aptitude for further and collaborative research, and 10. Continuity of Relation. The first five factors are related to mentoring needs and the remaining 5 are related to student behavior. In the following section, the data analysis is presented.

\section{Analysis}

Mentoring means advising, refining, reforming, correcting, putting the student on the right track and it is beyond mere guidance and corrections suggested in the research work, it involves, personality building, relationship building, community building, motivating for collective and collaborative work. Chan (2008) identified mentoring practices that include: Providing information and advice, Coaching, Exposure and visibility: making connections, Sharing personal stories and humor, Responsiveness, Validation, Providing feedback, and Reciprocal relationships. All these are identified to develop quality work, academic community for progressive and collaborative research. They all emphasize the aspect of personalized advice, relationship. Going one step ahead Friendship (Kram, 1985) and honest self-disclosure (Boyle \& Boice, 1998; Johnson, 2003) have been identified as significant mentor functions. As a matter of fact, all these things are the practices that are involved right from the beginning of the doctoral program, at all levels of the research work. Theoretically all these sound well, but practically the reality might be different. Let us see what experience reveals from the practical plane. The following would deal with analysis of the data/observations related to the ten identified factors of mentoring at different stages or areas of the research work where mentoring is essential.

\section{Identification of the Research Problem:}

Identification of the Research Problem is the first step in the General Model of Scientific Method of Investigation (Busha \& Harter, 1980). There are many students who do not have the idea of the sources of the problem. Figure 1 presents data on this aspect. The data of the present study

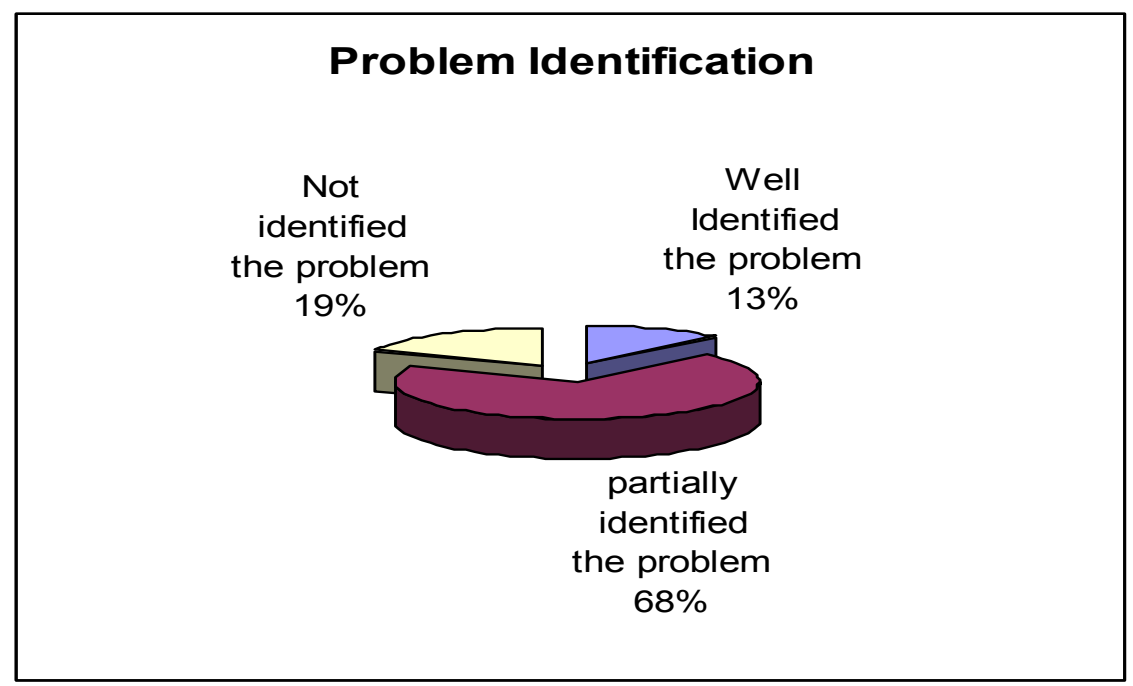

Figure 1: Identification of the Research Problem 
shows that only $13 \%$ of the students could efficiently identify the research problem. However, $68 \%$ of the students could come with a broad idea and $19 \%$ of the students did not come with any idea. They simply requested the supervisor (i.e., me) to suggest a topic. The above data suggests that the students should be provided with fair knowledge of the theory of research methodology. My experience is that, in spite of having a full paper (a paper is a course or a subject offered in an educational program) on Research Methodology at Masters Level, almost every Doctoral student does not apply the subject that they have learnt or studied at the Masters level. Most of the students who were suggested to select a significant problem, did not exhibit seriousness in selecting such problems. Here, Mentoring is essential in order to enable the student to select a significant problem, i.e. the problem that has social relevance.

\section{Agreement for the Finalization or Formulation of the Problem:}

As a mentor, the research supervisor, should suggest a significant problem or modify the problem that is identified by the student to make it more significant and feasible. When, modifications were suggested, as shown in Figure 2, 62\% of the students were convinced with the suggestions. However, $38 \%$ of the students were never convinced and they felt as if their wish to work on the identified areas is killed. They were almost upset. This indicates that these students come with a fixed frame of mind and they do not try to understand that whatever problem they identified is not that significant and feasible as the external and internal factors for the selection of the research problem suggest that their identified research problem is not a viable one. Here the role of mentor will be very delicate and crucial. Because, there is a chance for misunderstanding the fair and favorable intentions of the supervisor at the same time if supervisor does not advise the student properly there will be the incidence of selecting an area that is not feasible, and the students will not be able to complete their research work, as a result they turn out to be dropouts.

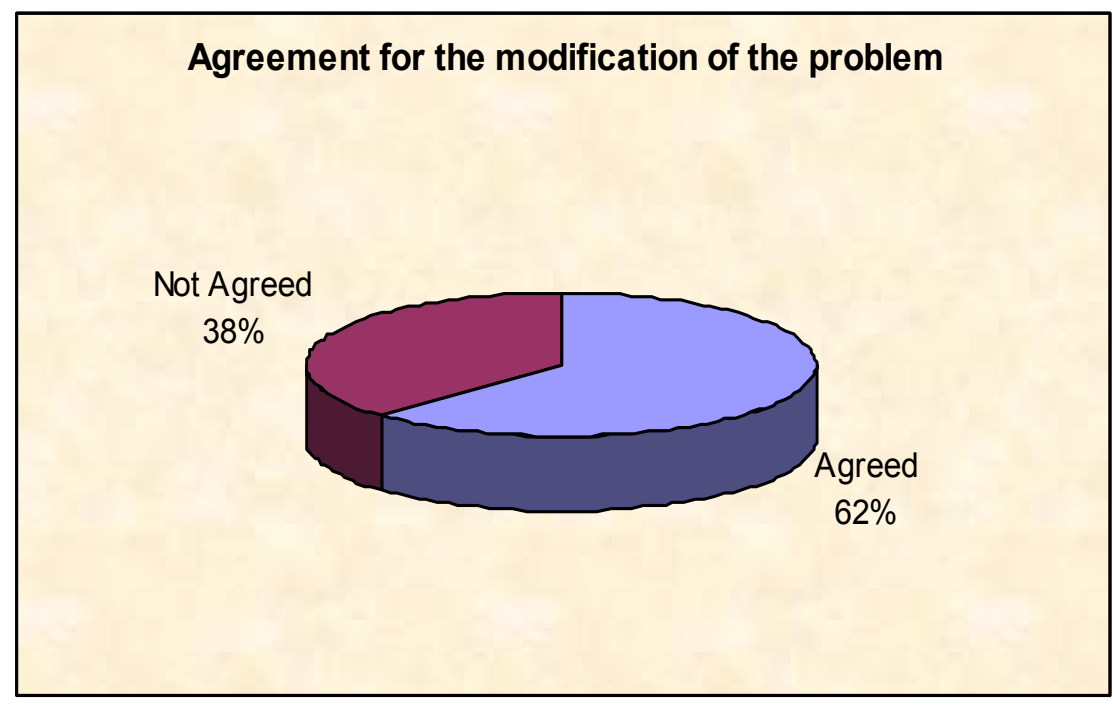

Figure 2. Agreement for the finalization or formulation of the Problem

\section{Formulation of the Problem and the Hypotheses}

Almost $100 \%$ of the scholars including the in-service men and Junior Research Fellowship (JRF) holders were not in a position to effectively and efficiently formulate the research problem and the hypotheses to be tested under the study. Most of them did not pay attention to the conceptual clarity and operational definitions of the important concepts related to the study. They could not formulate hypotheses that were directly related to the objectives of their research work. Here, 
again the supervisor has to do mentoring work. Similarly, deviation from the focus of the study and inability to report the results were also observed with almost all the students.

\section{Deviation from the Focus}

Research is a focused study. Right at the time of preparation of the proposal itself, there should be well focused approach. Almost $100 \%$ of the students deviate from the focus of the study. If the mentor is not perfect at his job, instead of mentoring, they may be misleading the students. There are instances where proper guidance was not provided. This is very dangerous. As a mentor, the supervisor should keep the scholar on the right track and see that there will be no deviation from the focus of the study, as almost every research scholar tends to deviate from the focus of the study. This has been observed for the past 20 years. It was not only with students of Masters Program, and M. Phil programs, even the Doctoral students also deviate from the focus of the study. As an adjudicator also, I had found that out of 12 works adjudicated, there was only one work that did not deviate from the focus. One more work was excellent half-way through. But at the stage of analysis and reporting the results, the deviation was miserable. This is how almost all works were found to have deviated from the focus. This is a very serious issue, because, after all, if the Doctoral student does not develop the capability of conducting a focused study, the purpose of the research work is violated. Basically, the Doctoral research work is not always aimed at coming out with new inventions, but it should ensure that the student develops the capability to carry out focused studies. It is basically, initiation to research; therefore, the scholars at least should learn the research methodology and understand the philosophy of research, the ethics of research and the basic concepts related to research methodology and develop research aptitude. Here mentoring is again essential.

\section{Reporting the Results}

As far as report writing is concerned $88 \%$ of the Students needed/need complete help, whereas $12 \%$ were/are able to write the technical/research report efficiently. It is almost the same case with M. Phil students also. As far as the students of Masters Program are concerned almost $100 \%$ of them needed complete help. Coming to the analysis of the Doctoral research reports of other students other than those who were guided by me, out of the adjudicated Doctoral dissertations, one was excellent, that is the initial chapters were written very well, but, the findings and actual results of the study were not presented well, two (15\%) were good, four $(31 \%)$ were below average and six (46\%) were hopeless. This shows that the Doctoral students in Non-English speaking countries need thorough corrections made by the supervisor. While making the corrections, as mentor, the supervisor should train them to correct themselves, because, after the Doctoral Program they have to carry out research on their own and there will be no guides/supervisors. This also implies that the supervisors also should be well versed with the language in which the research report is prepared in general and English in particular, as most of the research reports will be in English, excepting those that deal with particular language and literature as the field of study.

\section{Friendliness}

While carrying out Doctoral research work, both the student and the supervisor, can enjoy the research work, provided there is friendliness between them. Of course, every scholar respects the supervisor, but at the same time there will also be unpleasant behavior of the students at times, especially, when they become impatient, when the work is delayed (even though not deliberately), and when their mistakes are pointed out for rectification. This will also be the case with the impatience and arrogance of the supervisors. A supervisor with right philosophy of research supervision would certainly ensure friendly atmosphere. As far as my knowledge goes, every su- 
pervisor (there may be few exceptions) helps his or her research scholar with utmost commitment. But, the scholars may not perceive the same. The data in Figure 3 shows that only $69 \%$ of the Doctoral Students were very friendly, whereas 31\% were not friendly on the other hand some of them also misbehaved. What kind of research supervisor(s) these students would turn out to be in future. It is here and for this reason, the supervisor has to play a crucial role as mentor to inculcate the spirit of friendliness, humanity and human considerations with patience and forbearance. May be, if too much lenience and liberty is given to the students, they may take the supervisor for granted or for a ride. Therefore, the supervisor as a mentor also needs to strike a balance.

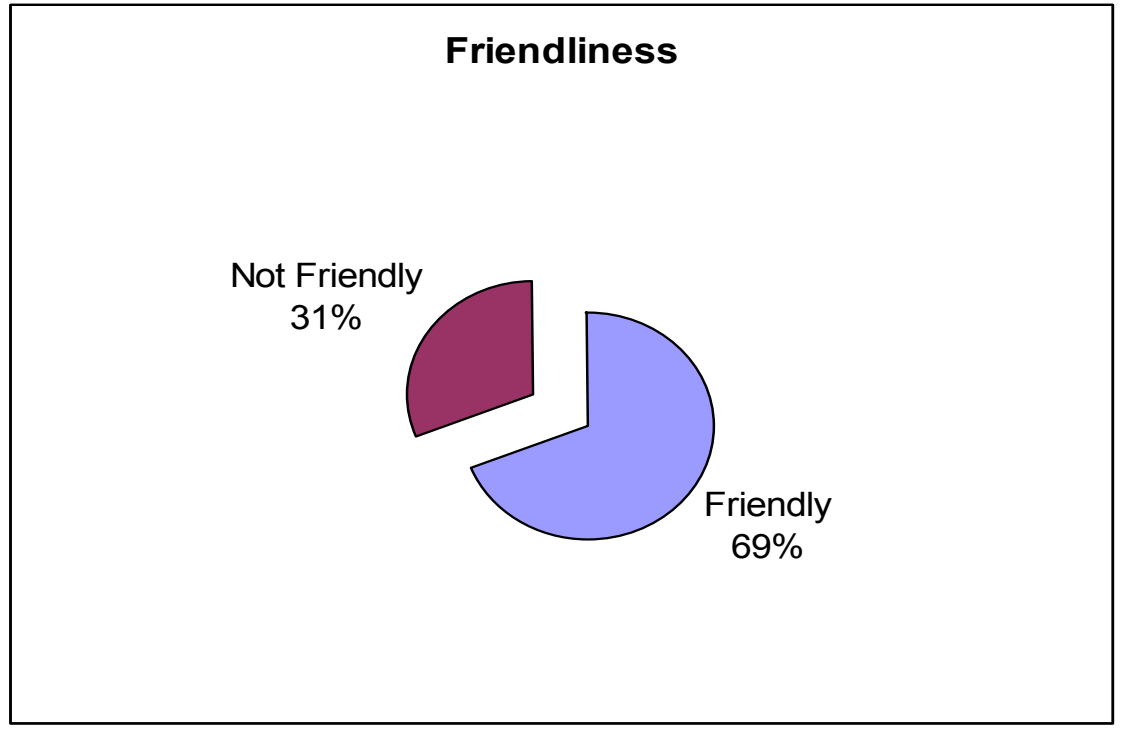

Figure 3. Friendliness

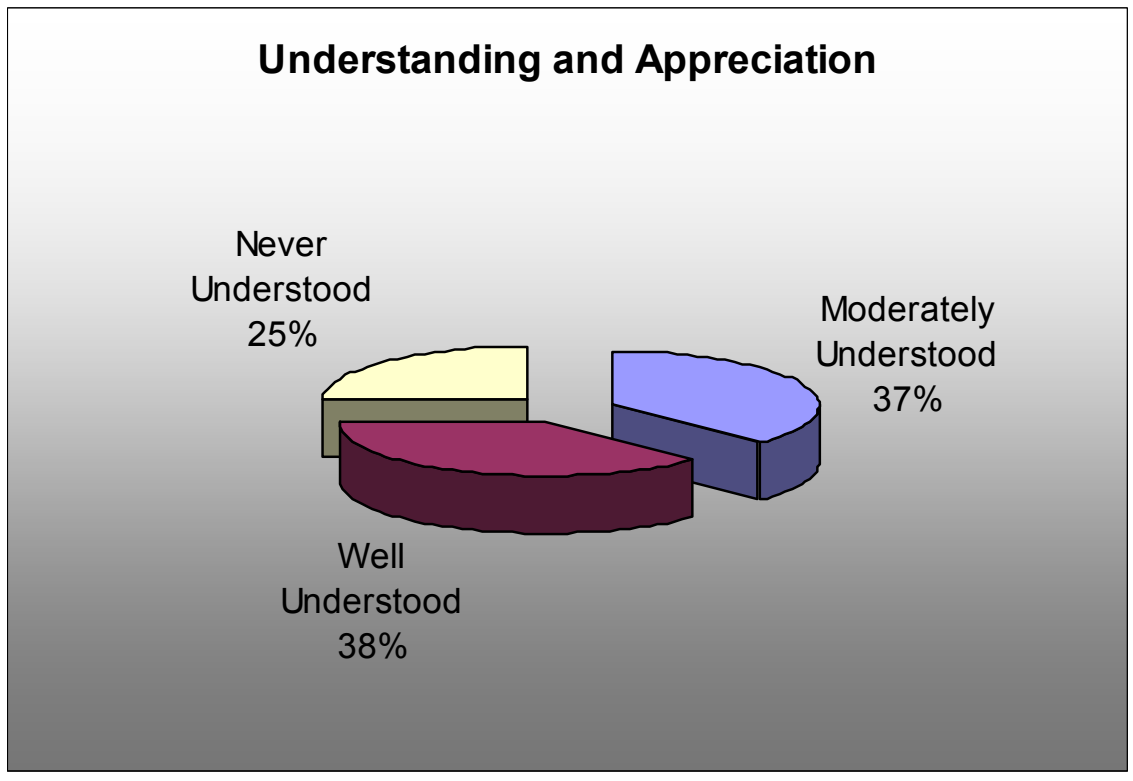

Figure 4. Understanding and Appreciation 


\section{Understanding and Appreciation}

At intellectual activity, the supervisors derive more satisfaction, when the scholars understand and appreciate their suggestions, perspectives, ideas, and contribution. This depends on level of understanding on the part of the students. Some will be totally indifferent and some do not bother. This is almost painful for a sincere supervisor. As shown in Figure 4, the study reveals that only $38 \%$ of the scholars understood and appreciated the supervisor very well, $37 \%$ have moderate understanding and 25\% never understood the supervisor. Moderate and well understood put together is $75 \%$, this gives a greater satisfaction that the Doctoral students by and large understand and appreciate the supervisor's efforts.

\section{Dropouts}

The most unfortunate and painful thing is the case of dropouts. In spite of laboring hard for their admission and identification of the problem and designing methodology when the Doctoral students dropout it causes much pain to the research supervisor. There are some who are very casual towards Doctoral research work, some are impatient, some are indifferent, and some are otherwise constrained due to work pressure relating to their jobs, transfers, etc. Whatever, may be the reason the result is a miserable dropout. Figure 5 shows that there was as much as $31 \%$ cases of dropouts at the level of Doctoral program. In fact, the percentage is more, i.e. to the extent of $50 \%$, but there is little ray of hope in case of some sincere and studious students that they may complete their work sooner or later. It can be inferred that the rate of dropouts is brought down substantially due to efficient mentoring process; otherwise, it would have been too high. There are some instances where the rate of dropouts is about $80 \%$ with some supervisors.

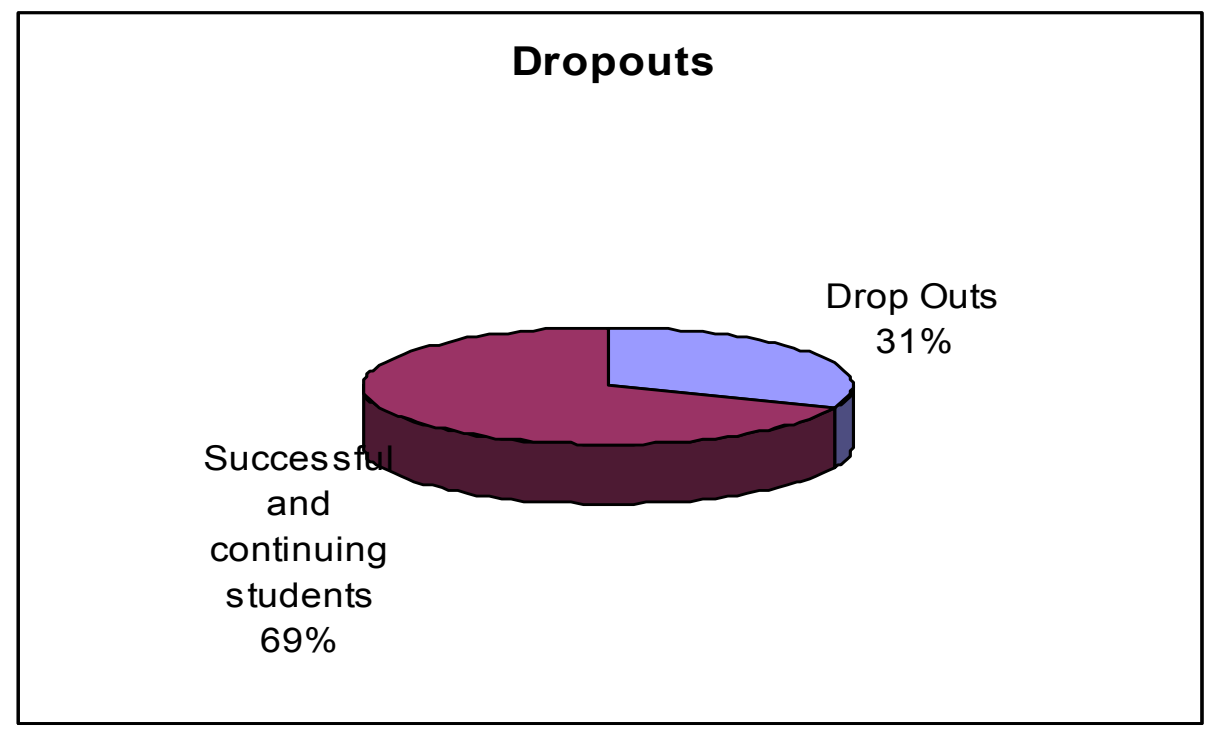

Figure 5. Dropouts

It is difficult to fix responsibility in this regard, even when the supervisor is liberal, cordial, cooperative, friendly and helpful, there are dropouts. It can be inferred that sheer indifference on the part of the scholars, dropouts take place. Of course, there are also exceptions that some may be very much constrained to continue their research work due to personal reasons, work pressures etc. But at the same time there are also cases of dropouts due to unhelpful and unfriendly supervisors. By and large, it is felt that the supervisor as a mentor should motivate the students to continue their work. But at the same time if the students do not approach the supervisor at all, how can the supervisor motivate the students. These are some of the sensitive and delicate issues; they 
need to be sorted out. For this we need to evolve some solutions or strategies. The problems of supervision of Doctoral research work get more complicated, as there is a shift in the research supervision models. Price and Money (2002), specify the options in research supervision models, viz.

\section{(a)The traditional model}

This is the traditional $\mathrm{PhD}$ university model in which there are (usually) two supervisors, both located in the home institution as is the (full-time or part-time) student. This model has severe limitations for senior managers in industry who, for example, need not to lose contact with their day-to-day responsibilities.

\section{(b)The semi-remote model}

This model still has a home-based supervisor but with a remotely based supervisor located close to a remotely domiciled student. It shares both some of the disadvantages and some of the advantages of the other two types of model. Where location permits, the students negotiate their preferred mentors and supervisors for whom they have respect and with whom there will be empathy.

\section{(c)The remote model}

This model has main supervision provided by two supervisors, both of whom are physically remote from the domicile of the student. Their location might be in the home institution, or one might be distant from both student and institution. There are complications for this model in the high international mobility of students.

The above models indicate the shift in the research supervision work. It can be easily percieved that there will be more problems for the students in remote model. Mentoring becomes imparative otherwise the rate of dropouts might be too high.

\section{Developing Aptitude for Further and Collaborative Research}

It will be a good sign if the Doctoral Research guidance gives rise to collaborative research between the student and the supervisor. This creates healthy research atmosphere. Thompson, McNeill, Sherwood, and Starck (2001) and Gray, Woodward, and Carter have described collaborative research as a means to enhance learning, attitudes and research capabilities in students. Yes, Collaborative research is more meaningful as more than one brain works on the research problem. Thus, this would give rise to finer and more systematic studies. The research supervisor as a mentor should motivate the students to develop the spirit of collaborative work, so that they develop the tendency to carry out collaborative work. But, this would be a tougher task for the supervisor, if the scholars are not interested in collaborative work or further research and if they misunderstand the intensions of the research supervisor behind the idea of collaborative work. There is a scope for misunderstanding that the supervisor would take advantage of the student, get everything done by the student and take credit for the work. This is unfortunate; this is where mentoring proves to be essential. Collaborative research and further research is the actual goal of the Doctoral research. If doctoral research is the end of it, how does research activity progress in the society? It means that there are higher levels and fairer goals or idea(s) behind academic research. The study revealed that there would be some students who will not be interested in collaborative work, may be due to many reasons. Figure 6 revealed that $63 \%$ of the scholars have not participated in collaborative research. It is $6 \%$ of the scholars who were involved in collaborative work for some time, and $31 \%$ of the scholars have participated in collaborative work. One important aspect that is noticed in this connection is, if the general academic culture is not 
conducive, whatever efforts the supervisor may put in, it will be difficult to motivate the scholars to participate in collaborative research.

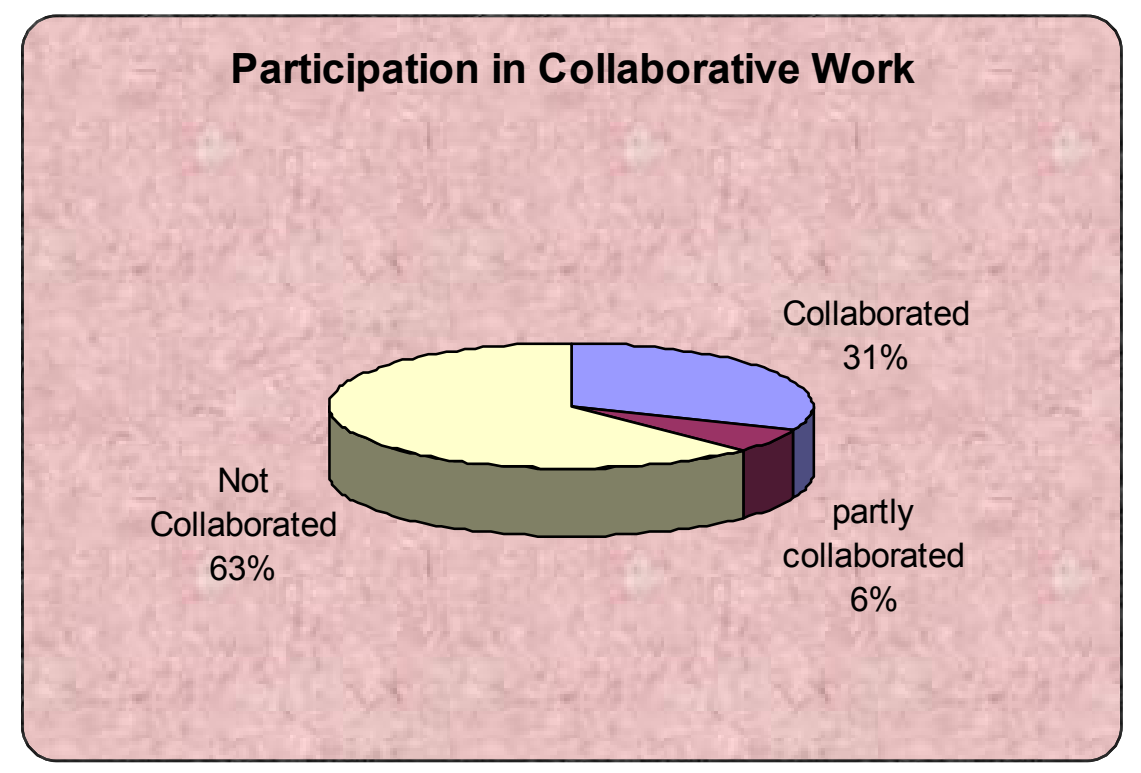

Figure 6. Developing Aptitude for Further and Collaborative Research

\section{Continuity of Relation}

The idea behind education is to build an ideal society and the idea behind academic research is to develop better academic communities that share their experiences, do collective and collaborative work and thereby build a healthy academic or research community. Quoting Bean, Readence, Barone, and Sylvester (2004) and Mullen (2005), Harris, Freeman, and Aerni (2009) note that "Successful mentoring for doctoral students is now seen to be built upon interaction, community, a sense of belonging, and student agency," a sense of belonging that is very essential, after all what is the use of education if it does not build communities with a sense of belonging.

The student-teacher relationship is considered to be most sacred relation in Indian culture. If not most sacred, at least some relation to further the cause of education and research. This is not un-

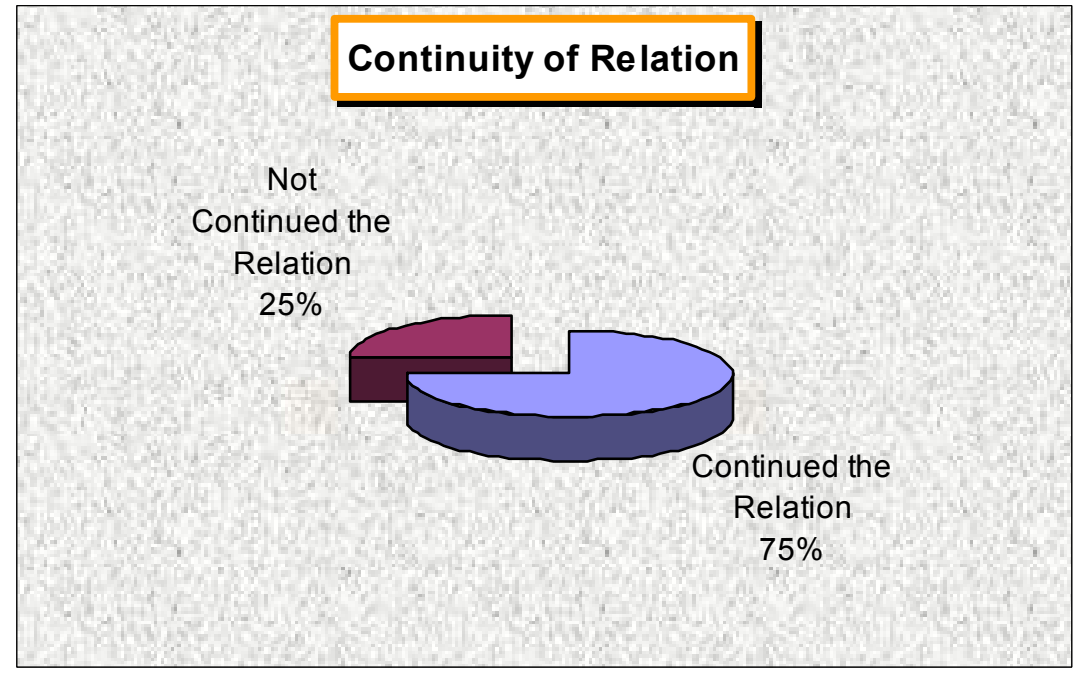

Figure 7. Continuity of Relation 
derstood by some of the students. They simply forget their mentor. The study shows through Figure 7 that $25 \%$ of the students have totally forgotten the supervisor; that means they seldom or never, contacted the supervisor after or during the research work, whereas a majority, $75 \%$ of the scholars, maintain and continue their relation with the supervisor. This is an indication that in India the students continue their relation with their supervisor. The minority of the students, who do not continue the relation, may be under the influence of other culture(s) or no culture. There is a need to do cultural engineering as part of effective mentoring task at the level of Doctoral research.

Relating to the above identified problems, there are some observations of the basic problems concerned with the Doctoral students and their research work. The following section presents the same.

\section{The Basic Problems}

There are a number of basic problems that are involved in academic research carried out by doctoral students. The following illustrates the same:

\section{Lack of understanding of the philosophy of research}

Most of the doctoral students feel that doctoral research means collecting of data on a given problem, analyzing the same and writing a thesis for the award of a degree. They do not come for the registration into Doctoral Research Program with an idea that it is a studious and systematic quest for facts that are relevant for social problems and these facts should provide solutions to the problems of life in general and human beings and human society in particular.

They do not understand the very basic principles and concepts of research that form the philosophy of research: the principle of objectivity vs. subjectivity, the concept of validity and reliability, the rationale behind the selection of a research problem. Most of the students join the program as it is compulsory for promotions in their jobs.

\section{Lack of fair theoretical knowledge of the field}

Most of them do not possess fair knowledge of either theory of research Methodology or the theory of the domain/subject field in which they wish to carry out their research work.

In the initial stages or at the time of admission, most of them do not understand the process of formulation of research problem and the hypotheses. They have least idea of the sources of the problem, the factors that influence the selection of the problems, the characteristics of a good hypothesis, types of hypothesis and the relevant methodology(ies) for verification of the hypothesis including the development of pertinent designs of proof.

Reasonable knowledge of the theoretical frame work of the field and the ability to use the theory for formulation of hypotheses will be lacking on most of the research scholars. It is at this stage the mentor plays a crucial role in bailing out the researcher. If at this stage mentoring and right guidance is not provided, the researcher will face irresolvable problems due to lack of conceptual clarity and finally he/she will be forced to discontinue his/her research work. Therefore, the role of mentor at every stage is very crucial, especially at the stage of problem identification and formulation of hypotheses or planning the objectives of the study.

\section{Dealing with hard nuts to crack}

There will be some research scholars who come with preconceived notions and research problems. They insist that the problem they selected has to be approved, though it will be an insignificant problem or a research problem that is not a feasible one. The supervisor needs to have 
tact to convince such scholars. Some come with a preconceived idea that the research supervisor does not know anything about research and he/she simply troubles the research scholars. Scholars with these notions initially behave well for want of admission. Later they become antagonistic, disobedient and critical. It is quite essential to mentor such doctoral students.

\section{The chain reaction}

The scholars who do not carry out systematic and meaningful study, if not guided or mentored properly would turn out to be bad and useless mentors of tomorrow. As a result substandard research works will be carried out and thus the legacy continues as a chain reaction. Therefore, every mentor has to realize his/her basic responsibility to discharge their job as a mentor meticulously and with utmost commitment. May be it is because of this chain reaction. Presently, there is considerable number of supervisors who do not possess the fair knowledge of Research methodology as a result they cannot ensure quality research work.

\section{Adjudication issues}

It may be due to lack of fair knowledge of the research methodology or the field of study, or due to personal and other considerations. Most of the adjudication reports are favorable though the quality of the work is very poor. This would add to the problem. It is observed that even foreign adjudicators also give excellent reports for very substandard works. This indicates that some of the foreign adjudicators also lack fair knowledge of research methodology or they are also not serious about the adjudication work. Keeping these reports in view, both the research scholars and the supervisors think that they are masters of research methodology and their work is a master piece. They boast themselves of carrying out a great work. They take it for granted, that whatever mistakes they make, as part of their research work, are not mistakes and their method or the approach is the right approach or the right method. Therefore, an adjudicator of a doctoral research work needs to be objective and he/she must accept the adjudication work only when he/she is confident about his/her knowledge of the research area and methods of research.

\section{Solutions}

The following may prove to be solutions to address the issues.

\section{Mentoring the Mentors}

First of all the Mentors need mentoring. There should be regularly organized intensive workshops on research methodology and mentoring of research supervisors. These workshops should be meticulously designed and the resource persons should be carefully selected on the basis of their reputation as an authority in research methodology. If it is required they may be encouraged to attend a short-term in-service training program on research methodology. The UGC-Academic Staff Colleges in India occasionally organize refresher/orientation courses on research methodology.

\section{A Paper on Research Methodology at Masters Level}

To develop research aptitude in the Doctoral Students, there should be a research methodology paper at the Master's level itself. It will add to the performance of the Doctoral students at that level, as they will have required background well before hand.

\section{Open Viva-Voce}

Open Viva-Voce Examination of the Doctoral Students makes them feel little more serious about their research work. It will certainly modify their behavior. Most of the Students feel that if they 
do not perform well at the open Viva, they lose their image in the professional or academic groups. Therefore, any student who is conscious of his image in the academic community would work studiously if there is an Open Viva-Voce Examination for the award of the Doctoral Degree after receiving the adjudication reports from the adjudicators. It will be one of the best practices, if one of the adjudicators is a member of the Open Viva-Voce Board of Examiners. The Practice in India varies from university to university, i.e. some universities invite the external adjudicator for the Viva-Voce, whereas some do not. However, by and large most of the universities have Open Viva-Voce Examinations, where anybody can attend the Viva and pose question to the scholar.

\section{Regular Exchange of Experiences of the Mentors at Exclusive, Seminars and Workshops}

At national and international levels there should be regular seminars, workshops, symposia, conferences, meetings, etc. to exchange experiences of the mentors. This would benefit the mentors in adopting other successful models and learn from others experiences.

\section{Presentation of Seminars by the Research Scholars}

We, in our university, as per the regulations, instruct the students to present two seminars in their research area. The scholar needs to present one seminar after Pre-Ph.D. Examination or after designing the methodology and the data collection tools and the second one, is called pre-

submission seminar, i.e. before submission of the thesis. These seminars are attended by all the faculty members, research scholars, professionals in the field, and P.G. students. This enables the research scholar to refine his study and rectify any errors.

\section{Regular and Personal Guidance and Interaction between the Mentor and the Student}

Mentoring is possible only when the student responds to the mentor, without regular interaction between the mentor and the student it will be very difficult to practice mentoring. Experience shows that even after regular interactions sometimes it will be difficult to mentor some students. I, from my personal side, ask my Doctoral students to maintain a research diary so that they would know the progress of their research work and also how many times they had interacted with the supervisor.

\section{Submission of Periodical Progress Reports}

Every Doctoral Student is required to submit Quarterly/Half yearly progress report. This is implemented to ensure regular review of the progress of the student's research work. This is also considered to be one of the best practices related to the Doctoral research work.

\section{Findings}

The findings from the above analysis and the personal experience of the author are:

1. Mentoring forms a very crucial component of Doctoral Research Supervision. Without mentoring it will be very difficult to ensure qualitative research work in the academic institutions. Besides ensuring quality, mentoring helps promote collaborative research, continued relationship between the system and the student by minimizing the number of dropouts.

2. Mentoring is essential at every stage of the research work, right from identification of the problem to report writing and beyond. 
3. Identification of the Research Problem: The study shows that only $13 \%$ of the students could efficiently identify the research problem. $87 \%$ of them either came with a broad idea or no idea of the research problem.

4. Agreement for the finalization or formulation of the Problem: $62 \%$ of the students were convinced with the suggestions, $38 \%$ of the students were never convinced.

5. Formulation of the Problem and the Hypotheses: Almost $100 \%$ of the scholars were not in a position to effectively and efficiently formulate the research problem and the hypotheses of the study.

6. Deviation from the Focus: Almost $100 \%$ of the students deviate from the focus of the study.

7. Reporting the Results: As far as report writing is concerned $88 \%$ of the Students needed/need complete help, whereas $12 \%$ were/are able to write the technical/research report efficiently.

8. Friendliness: $69 \%$ of the Doctoral Students were very friendly, whereas $31 \%$ were not friendly on the other hand some of them also misbehaved.

9. Understanding and appreciation: $25 \%$ never understood. Moderate and well understood put together is $75 \%$.

10. Dropouts: There were as much as $31 \%$ cases of dropouts at the level of Doctoral program.

11. Developing aptitude for further and collaborative research: $63 \%$ of the scholars have not participated in collaborative research, only $37 \%$ of the scholars have partly or fully participated/participating in collaborative work.

12. Continuity of Relation: $25 \%$ of the students have totally forgotten the supervisor, whereas, majority $75 \%$ of the scholars maintain and continue their relation with the supervisor.

13. It is noticed that, if the general academic culture is not conducive, no matter what efforts the supervisor may put in, it will be difficult to motivate the scholars to participate in collaborative research.

The matter of concern is that in spite of cordial and friendly mentoring, there are considerable instances of misunderstanding on the part of the students, almost a majority of them do not get inclined to do collaborative research on the other hand some of the students turn out to be dropouts and do not bother to continue relation with the Department or the supervisor. It may be with this reason Kram (1983) in her discussion of the initiation stage of mentoring echoes this logic by asserting that mentoring is more likely for protégés who are seen as having talent, drive, and positive attitudes toward their work.

However, the brighter side of it is some get really motivated to the fullest or desired extent, they also appreciate the suggestions made by the supervisors, enjoy their research work and participate in collaborative research and majority do continue their relation with the supervisor.

It is also felt that regular training of the mentors, providing a platform for exchange of views and experiences, and developing and implementing best practices would improve the quality of academic research work.

It is a fact, that the success of the supervisor, in supervising the Doctoral Students, can be attributed to his ability to mentor the students. It is also a fact, that lack of proper mentoring is the cause for high rate of dropouts at the Doctoral Research Progams. 


\section{Conclusion}

The credibility of a university depends on the quality of research work it carries out. This may not be taken seriously by the students, because, they come with a specific goal of obtaining the Degree without bothering much about the quality of work, significance of the study, etc. In view of this mentoring is very essential to guide, advise, motivate and reform these students so that they become habitual researchers in the future, and these students would contribute commendably to the growth of the literature in the field and also to the development of the nation. Adams (1992) opines that a mentor's role is essential to "hold the protégé to high standard of academic output." Noonan, Ballinger, and Black (2007) state, "A high quality doctoral program involves a range of educational experiences that extend beyond coursework. While coursework can provide critical content and skills for leadership roles in special education, coursework alone may not be sufficient to motivate and retain doctoral students, provide them with necessary experiences associated with future job responsibilities, or socialize them to their new leadership positions." Nyquist (2002) rightly points out that "The present-day efforts to look at doctoral education thus take place within a context different from previous occasions. Further, rapid and transformative changes are under way in all aspects of our society: in business and industry, in government and politics, in our society as a whole, and certainly within education. These circumstances require us to address the question, "How can the $\mathrm{PhD}$ meet the needs of the society of the 21 st century?" It is mentoring that proves to be one of the best solutions and practices to meet the needs and challenges of the changing times.

\section{References}

Adams, H. G. (1992). Mentoring : An essential factor in the doctoral process for minority students. National Center for Graduate Education for Minorities.

Adams, H. G., \& Conley. M. M. (1986). Minority participation in graduate education: An action plan. The report of the National Forum on the Status of Minority Participation in Graduate Education. Washington, D.C.

Bean, T. W., Readence, J. E., Barone, D. M., \& Sylvester, T. (2004). An interpretive study of doctoral mentoring in literacy. Mentoring \& Tutoring: Partnership in Learning, 12(3), 371-381.

Boyle, P., \& Boice, B. (1998). Best practices for enculturation: Collegiality, mentoring, and structure. In M. S. Anderson (Ed.), The experience of being in graduate school: An exploration (pp. 87-94). San Francisco: Jossey-Bass.

Busha, C. H., \& Harter, S. P. (1980). Research methods in librarianship: Techniques and interpretation. New York: Academic Press.

Chan, A. W. (2008). Mentoring ethnic minority, pre-doctoral students: An analysis of key mentor practices. Mentoring \& Tutoring: Partnership in Learning, 16(3), 263-277. DOI: 10.1080/13611260802231633

Collinson, J., \& Hockey, J. (1997). The social sciences training-model doctorate: Student choice? Journal of Further and Higher Education, 21, 373-381.

Deem, R., \& Brehony, K. J. (2000). Doctoral students' access to research cultures - Are some more unequal than others? Studies in Higher Education, 25(2), 149-165.

Dickinson, S. C., \& Johnson, W. B. (2000). Mentoring in clinical psychology doctoral programs. The Clinical Supervisor, 19(1), 137- 152. DOI: 0.1300/J001v19n01_08

Gray, R. W., Woodward, N. J., \& Carter, Y. H. (2001). Barriers to the development of collaborative research in general practice: a qualitative study. British Journal of General Practice, March, 221.

Ku, H-Y., Lahman, M. K. E., Yeh, H-T., \& Cheng, Y-C. (2008). Into the academy: Preparing and mentoring international doctoral students. Educational Technology Research and Development: International Review, 56(3), 365-377. DOI 10.1007/s11423-007-9083-0 
Harris, J. B., Freeman, T. L., \& Aerni, P. W. (2009). On becoming educational researchers: The importance of cogenerative mentoring. Mentoring \& Tutoring: Partnership in Learning, 17(1), 23-39. DOI: $10.1080 / 13611260802658546$

Jacobi, M. (1991). Mentoring and undergraduate academic success: A literature review. Review of Educational Research, 61, 505-532.

Johnson, W. B. (2003). A framework for conceptualizing competence to mentor. Ethics \& Behavior, 13(2), $127-151$.

Kram, K. E. (1983). Phases of the mentor relationship. Academy of Management Journal, 26, 608-625.

Kram, K. E. (1985). Mentoring at work: Developmental relationships in organizational life. Glenview: Scott, Foresman and Company.

Mullen, C.A. (2005). Fire and ice: Igniting and channeling passion in new qualitative researchers. New York: Peter Lang.

Noonan, M. J., Ballinger, R., \& Black, R. (2007). Peer and faculty mentoring in doctoral education: Definitions, experiences, and expectations. International Journal of Teaching and Learning in Higher Education, 19(3), 251-262.

Nyquist, J. D. (2002). The PhD: A tapestry of change for the 21st century. Change, 34(6), 12-20.

Price, D. C., \& Money, A. H. (2002). Alternative models for doctoral mentor organisation and research supervision. Mentoring \& Tutoring, 10(2), 127-135. DOI: 10.1080/1361126022000002446

Summers-Ewing, D. (1994). Mentoring: A vital ingredient for career success. Paper presented at the Annual Meeting of the American Psychological Association, Los Angeles, CA, 12-16 August 1994. ERIC, ED 378519.

Thompson, C. J., McNeill, J. A., Sherwood, G.D., \& Starck, P. L. (2001). Using collaborative research to facilitate student learning. Western Journal of Nursing Research, 23(5), 504-516.

\section{Biography}

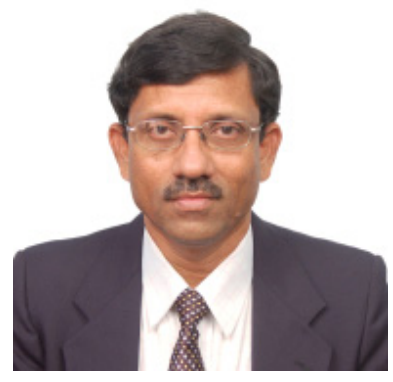

Dr. V. Vishwa Mohan, M.A., MLISc, Ph. D. (in Library and Information Science ), is presently Professor and Head, Department of Library and Information Science, Osmania University, Hyderabad, India. He was born in the year 1958. He was also Chairman, Board of Studies in Library and Information Science in the university for three terms. He was also Vice President and General Secretary of Indian Association of Teachers of Library and Information science. He has published over 60 research papers in the Indian and International journals and conference proceedings, three books and edited four books. He has produced four Ph.Ds and twelve M.Phils. 